\title{
Improving outcomes in cerebral palsy with early intervention: new translational approaches
}

\author{
Anna Purna Basu* and Gavin Clowry \\ Institute of Neuroscience, Newcastle University, Newcastle upon Tyne, UK \\ *Correspondence: anna.basu@ncl.ac.uk \\ Edited and reviewed by: \\ Eugene R. Schnitzler, Loyola University Medical Center, USA
}

Keywords: cerebral palsy, early intervention, translational medical research, diagnosis, outcome prediction

Cerebral palsy (CP) is defined as a group of permanent disorders of the development of movement and posture, causing activity limitation, attributed to non-progressive disturbances occurring in the developing fetal or infant brain (1). Lesions to the sensorimotor cortex, subcortical axon tracts, and subplate are often implicated, with other motor and non-motor areas frequently also affected. The etiology is complex and often multifactorial (2); causes include hypoxia (3), stroke (4), infection (5), trauma, and genetic factors (6). By the end of the second trimester, corticospinal axons have invaded the spinal gray matter and thalamic afferents the upper layers of the neocortex $(7,8)$. These systems undergo activity-dependent development $(9,10)$. After early brain injury, descending pathways are disrupted, with abnormal development of reflex and corticospinal circuitry $(11,12)$. Movement abnormalities are initially subtle but develop subsequently $(13,14)$. Aberrant post-lesional plasticity undoubtedly contributes to CP. It is misleading to suppose that developmental mechanisms are self-reparative. The challenge is to understand activity-dependent fine-tuning of neural circuitry during normal development and promote desirable plasticity while limiting undesirable effects following developmental lesions. However, before proposing interventions, we have to improve our outcome prediction skills.

Cerebral palsy affects 2/1000 live births (15): its prevalence is several times greater than spinal cord injury (SCI) and amyotrophic lateral sclerosis (ALS) (16), which also affect the corticospinal system. However, a Web of Science literature search for 2010-2014 using the phrases "cerebral palsy" (excluding supranuclear palsy), "spinal cord injury," and "amyotrophic lateral sclerosis" returned fewer publications for CP (6653) than SCI (16147) or ALS (8258). For the flagship journals Nature Neuroscience and Neuron, the difference was greater: just one return for $\mathrm{CP}$ compared with 39 for SCI and 63 for ALS. Thus, CP, which causes lifelong and often severe disability, is under-researched compared with other conditions that engage neuroscientists and neurologists. We proposed a "Frontiers in Neurology Research Topic" on improving outcomes in CP with early intervention, as a forum to promote CP-related research. We involved authors with expertise ranging from signaling pathways and stem cells through functional imaging and neurophysiology to non-invasive interventions in humans. Articles include long and short reviews, original research, and opinion pieces from basic scientists and clinicians. We achieved our aim in covering prediction of outcomes of pre- and perinatal lesions, basic research in animal models and human subjects, and ideas for, and trials of, early interventions.

Hadders-Algra (17) sets the scene with a comprehensive review summarizing early brain development and discussing the effect of lesions and implications for early diagnosis and intervention. Marcroft et al. (18) review developments in movement recognition technology for classifying spontaneous general movements in high-risk infants. This theme of technology-assisted assessment is further continued by Allievi et al. (19) who focus on the use of instrumented toys and robot-assisted assessment tools with functional MRI so that functional brain activity can be mapped in health and disease even in infancy. Taking a different approach to early detection, Douglas-Escobar et al. (20) explore the potential value of two serum biomarkers of brain damage and neurodevelopmental outcomes in neonates with hypoxic-ischemic encephalopathy (HIE), namely UCH-LI and GFAP.

We received a number of basic research articles relating to early brain injury. Alagappan et al. (21) show that the increase in neural precursor cell growth and proliferation in the subventricular zone after injury depends on insulin-like growth factor receptor signaling as well as EGRF. They discuss how the nature of the culture medium used could have obscured this important finding until now. Again at a signaling pathway level, Frasch (22) considers the role of adenosine monophosphate kinase (AMPK) in inducing adaptive fetal brain shut-down and suppressing pro-inflammatory responses in the context of worsening acidemia during labor. This opinion paper accompanies the article by $\mathrm{Xu}$ et al. (23), which explores in an ovine model the complex relationship between preceding chronic fetal hypoxia, acute and worsening acidosis, timing and duration of adaptive brain shut-down, and the degree of brain inflammation. They suggest that EEG monitoring in addition to fetal heart rate monitoring during labor may identify earlier those infants at risk of developing severe acidosis. The ovine model does shed light on the human situation but as ever, extrapolations between species must be done with caution. Clowry et al. (24) address this issue in detail in a review of the suitability of various animal models for testing early intervention approaches in $\mathrm{CP}$.

Moving from physiology to histology and detailed longitudinal neuroimaging, Kostovic et al. (25) characterize white matter lesions in preterm infants in terms of the developmental dynamics of "cellular compartments in the cerebral wall," 
demonstrating how if the precise location and timing of the insult is known, the axonal pathways affected can be predicted. Mackey et al. (26) also use neuroimaging to understand outcome, but in the context of established unilateral CP. In this setting, diffusion-weighted MRI-based fractional anisotropy in the posterior limb of the internal capsule correlates with upper limb functional assessments. They also demonstrate deficits in intracortical and interhemispheric inhibition in those with poor upper limb function.

We also solicited articles on early intervention approaches. Two of these covered cell therapy. Gonzales-Portillo et al. (27) explore the potential for stem cell therapy in neonatal HIE and the outstanding clinical issues to be addressed, while Li et al. (28) discuss umbilical cord blood cell therapies in preterm infants, focusing on white matter injury. The other two articles address non-invasive approaches in infants with unilateral brain damage. Friel et al. (29) review current knowledge of corticospinal tract development including genetic and activity-dependent influences, and describe interventional approaches potentially applicable to hemiplegic CP. Finally, Basu et al. (30) take a clinical standpoint, describing the problems faced in hemiplegic CP, traditional approaches to management and their limitations, and interventions currently under investigation in infants.

We thank everyone who has supported this enterprise by submitting or reviewing manuscripts. We hope this Research Topic will serve its purpose of showcasing some of the fascinating advances in CP research, and raising the profile of this important condition to promote further investigation, ultimately for the benefit of those affected.

\section{ACKNOWLEDGMENTS}

Dr. Basu is funded by a Career Development Fellowship award from the National Institute for Health Research. The views expressed in this publication are those of the author and not necessarily those of the NHS, the National Institute for Health Research, or the Department of Health.

\section{REFERENCES}

1. Rosenbaum P, Paneth N, Leviton A, Goldstein M, Bax M, Damiano D, et al. A report: the definition and classification of cerebral palsy April 2006. Dev Med Child Neurol Suppl (2007) 109:8-14.

2. Locatelli A, Incerti M, Paterlini G, Doria V, Consonni S, Provero C, et al. Antepartum and intrapartum risk factors for neonatal encephalopathy at term. Am J Perinatol (2010) 27(8):649-54. doi:10.1055/s-0030-1249761

3. Cowan F, Rutherford M, Groenendaal F, Eken P, Mercuri E, Bydder GM, et al. Origin and timing of brain lesions in term infants with neonatal encephalopathy. Lancet (2003) 361(9359):736-42. doi:10.1016/S0140-6736(03)12658-X

4. Volpe JJ. Brain injury in premature infants: a complex amalgam of destructive and developmental disturbances. Lancet Neurol (2009) 8(1):110-24. doi:10. 1016/S1474-4422(08)70294-1

5. Shatrov JG, Birch SC, Lam LT, Quinlivan JA, McIntyre S, Mendz GL. Chorioamnionitis and cerebral palsy: a meta-analysis. Obstet Gynecol (2010) 116(2 Pt 1):387-92. doi:10.1097/AOG.0b013e3181e90046

6. Moreno-De-Luca A, Ledbetter DH, Martin CL. Genetic insights into the causes and classification of the cerebral palsies. Lancet Neurol (2012) 11(3):283-92. doi:10.1016/S1474-4422(11)70287-3

7. Eyre JA, Miller S, Clowry GJ, Conway EA, Watts C. Functional corticospinal projections are established prenatally in the human foetus permitting involvement in the development of spinal motor centres. Brain (2000) 123(Pt 1):51-64. doi:10.1093/brain/123.1.51
8. Kostovic I, Judas M. Prolonged coexistence of transient and permanent circuitry elements in the developing cerebral cortex of fetuses and preterm infants. Dev Med Child Neurol (2006) 48(5):388-93. doi:10.1017/S0012162206000831

9. Martin JH. The corticospinal system: from development to motor control. Neuroscientist (2005) 11(2):161-73. doi:10.1177/1073858404270843

10. Khazipov R, Luhmann HJ. Early patterns of electrical activity in the developing cerebral cortex of humans and rodents. Trends Neurosci (2006) 29(7):414-8. doi:10.1016/j.tins.2006.05.007

11. Eyre JA. Corticospinal tract development and its plasticity after perinatal injury. Neurosci Biobehav Rev (2007) 31(8):1136-49. doi:10.1016/j.neubiorev. 2007.05.011

12. Hoon AH Jr, Stashinko EE, Nagae LM, Lin DD, Keller J, Bastian A, et al. Sensory and motor deficits in children with cerebral palsy born preterm correlate with diffusion tensor imaging abnormalities in thalamocortical pathways. Dev Med Child Neurol (2009) 51(9):697-704. doi:10.1111/j.1469-8749.2009. 03306.x

13. Hadders-Algra M. Putative neural substrate of normal and abnormal general movements. Neurosci Biobehav Rev (2007) 31(8):1181-90. doi:10.1016/j. neubiorev.2007.04.009

14. Spittle AJ, Boyd RN, Inder TE, Doyle LW. Predicting motor development in very preterm infants at 12 months' corrected age: the role of qualitative magnetic resonance imaging and general movements assessments. Pediatrics (2009) 123(2):512-7. doi:10.1542/peds.2008-0590

15. Oskoui M, Coutinho F, Dykeman J, Jette N, Pringsheim T. An update on the prevalence of cerebral palsy: a systematic review and meta-analysis. Dev Med Child Neurol (2013) 55(6):509-19. doi:10.1111/dmcn.12080

16. The Neurological Alliance. Neuro Numbers: A Brief Review of the Numbers of People in the UK with a Neurological Condition. London (2003).

17. Hadders-Algra M. Early diagnosis and early intervention in cerebral palsy. Front Neurol (2014) 5:185. doi:10.3389/fneur.2014.00185

18. Marcroft C, Khan A, Embleton N, Trenell M, Plötz T. Movement recognition technology as a method of assessing spontaneous general movements in high risk infants. Front Neurol (2014) 5:284. doi:10.3389/fneur.2014.00284

19. Allievi AG, Arichi T, Gordon AL, Burdet E. Technology-aided assessment of sensorimotor function in early infancy. Front Neurol (2014) 5:197. doi:10.3389/ fneur.2014.00197

20. Douglas-Escobar MV, Heaton SC, Bennett J, Young LJ, Glushakova O, Xu X, et al. UCH-L1 and GFAP serum levels in neonates with hypoxic-ischemic encephalopathy: a single center pilot study. Front Neurol (2014) 5:273. doi:10. 3389/fneur.2014.00273

21. Alagappan D, Ziegler AN, Chidambaram S, Min J, Wood TL, Levison SW. Insulin-like growth factor receptor signaling is necessary for epidermal growth factor mediated proliferation of SVZ neural precursors in vitro following neonatal hypoxia-ischemia. Front Neurol (2014) 5:79. doi:10.3389/fneur.2014.00079

22. Frasch MG. Putative role of AMPK in fetal adaptive brain shut-down: linking metabolism and inflammation in the brain. Front Neurol (2014) 5:150. doi: $10.3389 /$ fneur. 2014.00150

23. Xu A, Durosier LD, Ross MG, Hammond R, Richardson BS, Frasch MG. Adaptive brain shut-down counteracts neuroinflammation in the near-term ovine fetus. Front Neurol (2014) 5:110. doi:10.3389/fneur.2014.00110

24. Clowry GJ, Basuodan R, Chan F. What are the best animal models for testing early intervention in cerebral palsy? Front Neurol (2014) 5:258. doi:10.3389/ fneur.2014.00258

25. Kostovic I, Kostovic-Srzentic M, Benjak V, Jovanov-Milosevic N, Rados M. Developmental dynamics of radial vulnerability in the cerebral compartments in preterm infants and neonates. Front Neurol (2014) 5:139. doi:10.3389/fneur. 2014.00139

26. Mackey A, Stinear C, Stott S, Byblow WD. Upper limb function and cortical organization in youth with unilateral cerebral palsy. Front Neurol (2014) 5:117. doi:10.3389/fneur.2014.00117

27. Gonzales-Portillo GS, Reyes S, Aguirre D, Pabon MM, Borlongan CV. Stem cell therapy for neonatal hypoxic-ischemic encephalopathy. Front Neurol (2014) 5:147. doi:10.3389/fneur.2014.00147

28. Li J, McDonald CA, Fahey MC, Jenkin G, Miller SL. Could cord blood cell therapy reduce preterm brain injury? Front Neurol (2014) 5:200. doi:10.3389/fneur. 2014.00200

29. Friel KM, Williams PT, Serradj N, Chakrabarty S, Martin JH. Activity-based therapies for repair of the corticospinal system injured during development. Front Neurol (2014) 5:229. doi:10.3389/fneur.2014.00229 
30. Basu AP, Pearse J, Kelly S, Wisher V, Kisler J. Early intervention to improve hand function in hemiplegic cerebral palsy. Front Neurol (2014) 5:281. doi:10.3389/ fneur.2014.00281

Conflict of Interest Statement: The authors declare that the research was conducted in the absence of any commercial or financial relationships that could be construed as a potential conflict of interest.

Received: 17 January 2015; accepted: 29 January 2015; published online: 11 February 2015.
Citation: Basu AP and Clowry G (2015) Improving outcomes in cerebral palsy with early intervention: new translational approaches. Front. Neurol. 6:24. doi: 10.3389/fneur.2015.00024

This article was submitted to Neuropediatrics, a section of the journal Frontiers in Neurology.

Copyright (c) 2015 Basu and Clowry. This is an open-access article distributed under the terms of the Creative Commons Attribution License (CC BY). The use, distribution or reproduction in other forums is permitted, provided the original author (s) or licensor are credited and that the original publication in this journal is cited, in accordance with accepted academic practice. No use, distribution or reproduction is permitted which does not comply with these terms. 